\title{
Cutaneous blastomycosis as a malodorous wound
}

\section{Daniel Hekman, Sahand Rahnama-Moghadam}

Indiana University School of Medicine, Indianapolis, IN 46202, USA

Corresponding author: Dr. Daniel Hekman, E-mail: dhekman@iu.edu

Sir,

A 70-year-old male presented himself with a nonhealing wound over the right lower extremity, which had grown slowly over the course of six months (Fig. 1). Additional symptoms included pain accompanying movement of the leg and a malodorous smell. The patient had a notable history of living in a rural area in Indiana for many years and working as a farmer. No one in his household displayed similar lesions. Histopathologic findings showed broad-based budding yeast surrounded by neutrophils (Fig. 2). Gomori methenamine silver and periodic acid-Schiff stains and a fungal culture confirmed the diagnosis of Blastomyces dermatitidis. Despite the absence of respiratory complaints, subsequent CT imaging of the chest showed a $2.7 \times 1.1 \times 1.2 \mathrm{~cm}$ soft tissue density in the anterior upper lobe of the right lung. The patient was placed on a prolonged course of oral itraconazole with a slow resolution of the pulmonary and cutaneous ailments.

Cutaneous blastomycosis typically manifests itself after hematogenous spread from a primary source in the lungs, even in the absence of florid pneumonia [1]. Less often, Blastomyces dermatitidis can directly infect the skin, resulting in cutaneous blastomycosis [2]. These skin lesions are most often described as ulcerative or verrucous; however, they present themselves in a wide array of ways, including nodules, pustules, papules, and abscesses [3]. The most frequent extrapulmonary site is the skin, occurring in about $12 \%$ to $18 \%$ of cases. The face and extremities are commonly involved. In patients with multiple systems affected, approximately $77 \%$ have skin involvement. As many as $50 \%$ of blastomycosis cases may be without symptoms, with cutaneous involvement as the only sign of infection [4].

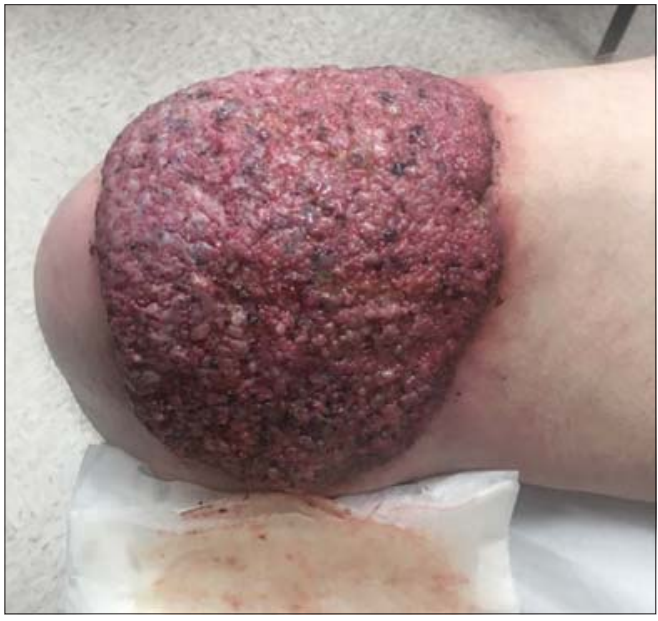

Figure 1: A gross image of the patient with cutaneous blastomycoses showing notable hyperkeratotic, verrucous, mounded nodules with a gray to violaceous border.

Although local blastomycosis outbreaks have been reported, most cases are sporadic. Endemic areas include the Midwestern states, as in the case of our patient, the Southeastern states, the Mississippi and Ohio River Basins, and the Canadian provinces near the Great Lakes. Despite initial reports of endemic cases affecting mostly middle-aged men performing outdoor occupations, a review of the reported outbreaks showed that such cases were not limited by sex, age, race, or occupational and seasonal predilections. Exposure to soil through work or recreational activities, typically near bodies of water, appears to be the most common factor associated with infection [5].

Two types of these cutaneous lesions are commonly distinguished [6]. They may appear as papules that progress to hyperkeratotic, verrucous, mounded nodules with a gray to violaceous border and with or without surrounding pustules, as in our patient. Less commonly, they may also develop a superficial ulcer 


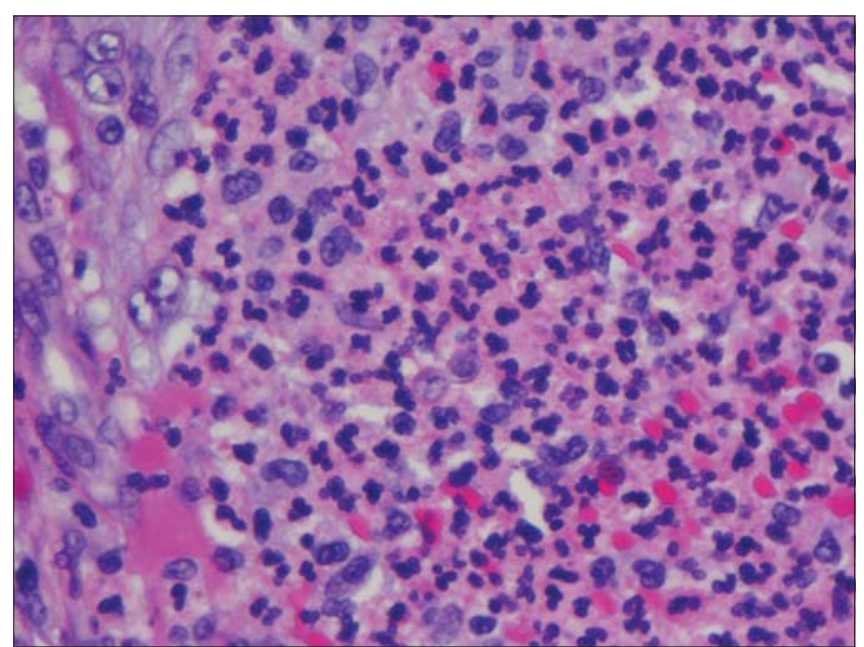

Figure 2: Histopathologic findings from a lesion showing broad-based budding yeast surrounded by neutrophils.

surrounded by an elevated border and an underlying base of friable granulation tissue. Differential diagnosis includes pyoderma gangrenosum and squamous cell carcinoma.

Diagnosis is confirmed by culturing tissue samples of the organism and/or visualizing thick-walled, broadbased budding organisms on pathology slides. Wet mounts obtained by touching a glass microscope slide to the wet exudate of the wound surface and stained for fungal spores may visualize organisms as well. Currently, serologic testing has not proven effective in diagnosing blastomycosis.

Since there is no operative national surveillance, the incidence of infection remains unknown. In the endemic area of Wisconsin, the average annual incidence rate between 1986 and 1995 was 1.4 cases per
100,000 persons. Accurate diagnosis of blastomycosis with appropriate evaluation is important, especially as its mortality falls at around 4\%, even with treatment [7].

\section{Consent}

The procedures followed were in accordance with the ethical standards of the responsible committee on human experimentation (institutional and national) and with the Helsinki Declaration of 1975, as revised in 2000 and 2008.

\section{REFERENCES}

1. Mason AR, Cortes GY, Cook J, Maize JC, Thiers BH. Cutaneous blastomycosis: a diagnostic challenge. Int J Dermatol. 2008;47:824-30.

2. Jiang Y, Dukik K, Munoz J, Sigler L, Schwartz IS, Govender NP, et al. Phylogeny, ecology and taxonomy of systemic pathogens and their relatives in Ajellomycetaceae (Onygenales): Blastomyces, Emergomyces, Emmonsia, Emmonsiellopsis. Fungal Diversity. 2018;90:245-91.

3. Azar MM, Assi R, Relich RF, Schmitt BH, Norris S, Wheat LJ, et al. Blastomycosis in Indiana: clinical and epidemiologic patterns of disease gleaned from a multicenter retrospective study. Chest. 2015;148:1276-84

4. Saccente M, Woods GL. Clinical and laboratory update on blastomycosis. Clin Microbiol Rev. 2010;23:367-81.

5. McTaggart LR, Brown EM, Richardson SE. Phylogeographic analysis of Blastomyces dermatitidis and Blastomyces gilchristii reveals an association with North American freshwater drainage basins. PLoS One. 2016;11:e0159396.

6. Chapman SW, Sullivan DC. Blastomyces dermatitidis. In: Mandell GL, Bennett JE, Dolin R, eds. Mandell, Douglas, and Bennett's Principles and Practice of Infectious Diseases. Philadelphia, PA: Churchill Livingstone/Elsevier; 2010:3319-32.

7. Khuu D, Shafir S, Bristow B, Sorvillo F. Blastomycosis mortality rates, United States, 1990-2010. Emerg Infect Dis. 2014;20:1789-94.

Copyright by Daniel Hekman, et al. This is an open access article distributed under the terms of the Creative Commons Attribution License, which permits unrestricted use, distribution, and reproduction in any medium, provided the original author and source are credited. Source of Support: Nil, Conflict of Interest: None declared. 